\title{
Serum levels of macrophages migration inhibitory factor in patients with coetaneous warts
}

\author{
Essam Eldeen A Nada, Hanan A Metwally, Mohammed A Ali, Amaal M \\ Mohammed .
}

\section{Abstract \\ Background}

Coetaneous warts are benign papillomas of the skin of which common warts and plantar warts are the most common types. Up to one third of primary school children have coetaneous warts. Warts are caused by infection with human papillomavirus (HPV)

\section{Objective}

to investigate the serum levels of MIF in patients with coetaneous warts from the outpatient clinic of the Dermatology and Venereology Department, Nag- Hamady general hospital during the period from 1-1-2015 to 1-1- 2016

\section{Results}

This study included 50 patients with clinical evidence of different types of coetaneous warts and 20 healthy control participants. In this study, there was a statistically significant difference between serum levels of MIF in the patients and controll subject $\mathbf{p}$ value $=\mathbf{0 . 0 2}$ ). The serum levels of MIF were lower in the patients than control subjects

\section{Conclusion}

It is study concluded that there was statistically significant low serum levels of MIF in patients with different types of coetaneous warts compared with healthy participants

\section{Introduction}

Coetaneous warts are benign papillomas of the skin of which common warts and plantar warts are the most common types. Up to one third of primary school children have coetaneous warts (1). Warts are caused by infection with human papillomavirus (HPV) (2). There are many types of coetaneous warts as common warts, plantar, flat warts usually appearing on the face, butcher's warts of the hands and fingers, and oral, gentialoranogenital warts (3).

Substantial effort has been directed at understanding the role of the host's immune response in the natural history of HPV. The most evidence for the association between cellular immune defects and HPV infection and related morbidities comes from persons with Human immunodeficiency virus (HIV) infection and renal transplantation.
Such individuals show increased prevalence of HPV infection as well as longer periods of persistence due to impaired cell mediated immunity in contrast to patient with intact immunity (4).

Macrophage migration inhibitory factor (MIF) is a protein encoded by the MIF gene and considered as a critical immunoregulatory cytokine. It has been re-evaluated as a proinflammatory cytokine and plays a role in the regulation of macrophage function in host defense. MIF exists in human epidermis, monocytes/macrophages, $\mathrm{T}$ cells, B cells, endocrine, and epithelial cells. In the field of dermatology, MIF is believed to be a criminal agent in many diseases such as allergic and irritant contact dermatitis, atopic dermatitis, psoriasis, vitiligo, alopecia areata, pemphigus valgaris and bullous pemphigoid (5).Considering that MIF has been manifested to be involved in the immunopathogenesis of cutaneous 
SOHAG MEDICAL JOURNAL

Vol. 21 No.2 July 2017 disorders; production of novel generations of the chemical or herbal preparations selective targeting of MIF, anti-MIF antibody and specific chemical MIF inhibitors can be the valuable therapeutic avenues in the future for the treatment of MIF-related dermatologic disorders (6).

There is no any previous study investigate the serum levels of MIF cytokine profile in the patients with coetaneous warts. So, this present study aimed to investigate serum levels of MIF in patients with different coetaneous warts compared with healthy control participants.

\section{2-Aim of work}

The aim of this work is to investigate the serum levels of MIF in patients with the coetaneous warts.

\section{3-Patients and Methods}

This study was designed as a case controlled study to investigate the serum levels of MIF in patients with coetaneous warts. This study included 50 patients with clinically evdent different types of coetaneous warts and 20 healthy control subjects from the outpatient clinic of the Dermatology and Venereology Department, NagHamady general hospital during the period from 1-1-2015 to 1-1- 2016.

The study was approved by the Research and Ethical Committees at Sohag Faculty of Medicine, Sohag University. Informed written consent was obtained from all patients and healthy control subjects before inclusion in the study.

Patients with the following criteria were included:

both sex (males and females), any age, and all types of coetaneous warts.

Patients with history of one of the following conditions were excluded: pregnant and lactating females, concomitant treatment of warts, concomitant intake of immunosuppressive drugs as (cyclosporine, azathioprine, methotrexate and prednisolone), and systemic diseases as (diabetes, hypertension, renal or heart diseases). All the patients were subjected to complete medical history included (age, sex, occupation, special habits). All the patients were subjected to complete general and local examination (number of warts, type of warts, onset, course, duration of the warts, family history of warts, history of recurrence of warts and medical history). The diagnosis of coetaneous warts was confirmed in all patients by 2 dermatological residents based on established clinical diagnosis of the coetaneous warts.

The control group was composed of healthy volunteers with no history of systemic diseases or immunosuppressive drugs during the previous three weeks prior to the study. Macrophage migration inhibitory factor levels were determined by enzyme- linked immunosorbent assay (ELISA). (MIF ELISA kits) Wuhan ELA ab science.com, Ltd, China.

Venous blood samples $(5-10 \mathrm{~mL})$ of all patients were collected between 09:00 and 11:30 A.M. in vacutainer tubes, without anticoagulant, under sterile conditions.

\section{Test principle:}

The microtiter plate (well) provided in this kit has been pre-coated with an antibody specific to MIF. Standards or samples were added to the appropriate microtiter plate wells with a biotinconjugated polyclonal antibody preparation specific for MIF and Avidin conjugated to Horseradish Peroxidase (HRP) was added to each microplate well and then incubated, a TMB substrate solution was then added to each well.

Only those wells that contain MIF, biotin-conjugated antibody and enzyme- conjugated Avidin exhibited a change in color. The enzyme-substrate reaction was terminated by the addition 
SOHAG MEDICAL JOURNAL

Vol. 21 No.2 July 2017 of a sulphuric acid solution and the color change was measured spectrophotometrically at a wavelength of $450 \mathrm{~nm} \pm 2 \mathrm{~nm}$. The concentration of MIF in the samples is then determined by comparing the Optic dense (OD) of the samples to the standard curve.

\section{Sample collection:}

Serum samples were collected in a separator tube and allowed to be clotted for 30 minutes before centrifugation for 15 minutes at approximately $1000 \times \mathrm{g}$.

\section{Assay procedure:}

All reagents were allowed to reach at room temperature, well mixed and avoid foaming.

1. $100 \mu \mathrm{l}$ of standard, blank, or sample was added per well, covered with a plate sealer and incubated for 2 hours at $37 \mathrm{C}^{\circ}$.

2. The liquid of each well are removed, didn't washed. $100 \mu \mathrm{l}$ of detection reagent (A) working solution to each well were added, covered with the plate sealer, incubated for 1 hour at $37 \mathrm{C}^{\circ}$.

3. Each well was aspirated and washed, repeating the process three times for a total of three washes, washing was by filling each well with wash buffer (approximately $400 \mu \mathrm{l}$ ) using a squirt bottle. After the last washing, any remaining wash buffer is removed by decanting, and then the plate was inverted and blotted against clean paper towels.

4. $100 \mu \mathrm{l}$ of detection reagent (B) working solution was added to each well, covered with a new plate sealer and incubated for 1 hour at $37 \mathrm{C}^{\circ}$.
5. The aspiration and washing were repeated as in step 4.

6. $90 \mu \mathrm{l}$ of substrate solution are added to each well, covered with a new plate sealer, incubated within 15-30 minutes at $37 \mathrm{C}^{\circ}$ and protected from light.

7. $50 \mu \mathrm{l}$ of stop solution is added to each well and the plate was gently tapped to ensure thorough mixing.

8. Determine the optical density of each well at once, using a microplate reader set to $450 \mathrm{~nm}$.

\section{Specificity}

This assay recognizes recombinant and natural human MIF. No significant cross-reactivity or interference was observed.

Detection Range

0.312 - $20 \mathrm{ng} / \mathrm{ml}$.

\section{Statistical analysis}

Data was analyzed using STATA intercooled version 12.1. Quantitative data was represented as mean, standard deviation, median and range. As the data was not normally distributed Kruskal-Wallis rank test for comparison of three or more groups and Mann-Whitney test was used to compare two groups. Qualitative data was presented as number and percentage and compared using Chi square test. Spearman's correlation and Pearson's correlation analysis also was used to determine the correlation between two continuous variables. $\mathrm{P}$ value was considered significant if it was less than 0.05 .

\section{Results}

This study included 50 patients with clinical evidence of different types of cutaneous warts and 20 healthy control participants. The mean (SD) age of patients was 22.18 (10.56) years and the mean (SD) age of control subjects was 26.6 (12.42) years with no significant difference between the two groups as regard age. The study included 50 patients [35 males (70\%) and 15 females (30\%)], and 20 healthy control subjects [12 males (60\%) and 8 female (40\%)], with no significant difference between the two groups as regard sex (Table 1). 
SOHAG MEDICAL JOURNAL

Vol. 21 No.2 July 2017
Serum levels of macrophages migration inhibitory factor Amaal M Mohammed.et al

Table (1). Age and sex of studied population

\begin{tabular}{|l||c||c|c|}
\hline Variable & Cases & Controls & P value \\
\hline \hline Age/years & & & \\
Mean (SD) & $22.18(10.56)$ & $26.6(12.42)$ & 0.12 \\
Median (range) & $22(2-61)$ & $27.5(8-48)$ & \\
\hline \hline Sex & & & 0.42 \\
Females & $15(30 \%)$ & $8(40 \%)$ & $12(60 \%)$ \\
Males & $35(70 \%)$ & & \\
\hline
\end{tabular}

P value $<0.05$ was significant. SD: standard deviation

In this study, there was a statistically significant difference between serum levels of MIF in the patients and controls subject $\mathbf{p}$ value= $\mathbf{0 . 0 2}$ ). The serum levels of MIF were lower in the patients than control subjects (Table 2).

Table( 2). Comparison of patients and controls regarding serum levels of macrophage migration inhibitory factor (Table 2)

\begin{tabular}{|l||c|c||c|}
\hline Variable & Cases & Controls & P value \\
\hline \hline Macrophage & & & \\
inhibition factor & $4.13(3.15)$ & $5.1(1.65)$ & 0.02 \\
Mean (SD) & $3.4(0.1-19.1)$ & $4.8(2.1-7.8)$ & \\
Median (range) & & & \\
\hline
\end{tabular}

MIF:macrophage migration inhibitory factor. SD: standard deviation $\mathbf{P}$ value $<0.05$ was significant.

\section{Discussion}

Coetaneous warts are benign epithelial tumors generally caused by infection by human papilloma virus (7).They are very common and affect $7-12 \%$ of the population (8).

Cell-mediated immunity (CMI) plays a significant role in wart regression. The association between cellular immune defects and HPV infection and related morbidities comes from persons with HIV infection. Such individuals show increased prevalence of anogenital HPV infection (9), as well as longer

periods of HPV persistence. In addition, infection with multiple HPV types and with oncogenic types is more common (10).

The macrophage migration inhibitory factor (MIF) was one of the first cytokines discovered in the early $60^{\prime} \mathrm{s}$. Its broad range of immunologic effects and its expression by a variety of cells, including $\mathrm{T}$ cells and macrophages, suggest a fundamental role in the regulation of immune responses. Its name was derived from the first well-known function of the protein, namely the inhibition of the migration of macrophages (11).

Although MIF was first identified as an inhibitor of macrophage migration (12), depletion of MIF reduces leukocyte accumulation in models of infection/endotoxemia, arthritis and atherogenesis (13). Nonetheless, MIF clearly induces adhesion and migration of monocyte- lineage cells in postcapillary venules (14).

The MIF is a regulator of innate immunity and helps macrophage in its functions such as phagocytosis, adherence, spreading, and metabolism (15). MIF acts as the inflammatory mediator to stimulate the expression of the cytokines like TNF- $\alpha$, IL1, IL-6 (16).

Apart from the inflammatory and immunological functions, MIF is considered to play a role in cell proliferation and differentiation (17). MIF inhibits regulatory 
effects on cytotoxic $\mathrm{CD}^{+} \mathrm{T}$ cells and regulates lymphocyte trafficking. So, MIF has important immunomodulatory functions in the adaptive immune system (18). No previous studies investigated the serum levels of MIF in patient of coetaneous warts. So the present is conducted to investigate the serum level of MIF in the patient of coetaneous warts.

The present study found that there was a statistically significant difference between serum levels of MIF in patients with different coetaneous warts and healthy control participants. Serum levels of MIF were significantly decreased in the patients with coetaneous warts. So, this low serum level of MIF could be an important immunological factor for increasing the risk of HPV infections and development in different coetaneous warts.

\section{Summary:}

Coetaneous Warts are the coetaneous manifestations of Human Papilloma Virus (HPV). Warts may exist in different forms Common warts, planter warts, flat or plane warts, and genital warts. Transmission of HPV often happens when skin comes in contact with the virus from person to person, especially in close circles like families. The infection is combated by the body's cell-mediated immunity, mainly the T cells. Patients with cell mediated immunity deficiency are particularly susceptible to HPV infection and are difficult to treat.

The serum levels of MIF cytokine profile were not studied in coetaneous warts before. This present study aimed to investigate the serum levels of MIF in patients with different coetaneous warts by ELISA compared with healthy control participants.

The present study found that there was a statistically significant difference between serum levels of MIF in patients with different coetaneous warts and healthy control participants. Serum levels of MIF were significantly decreased in the patients with coetaneous warts. So, this low serum level of MIF could be an important immunological factor for increasing the risk of HPV infections and development in different coetaneous warts.

\section{Conclusion:}

It is study concluded that there was statistically significant low serum levels of MIF in patients with different types of coetaneous warts compared with healthy participants that may contribute to development and maintenance of different types of coetaneous warts which depend mainly on the defect of cell mediated immunity.

\section{Recommendations:}

1-Future studies on large numbers of patients are required to investigate serum levels of MIF in patients with different coetaneous warts.

2-Future studies are required to compare the results of serum levels and tissue levels of MIF in patients with different coetaneous warts and healthy participants.

3-Future studies are required to investigate the clinical efficacy of topical and systemic administration of MIF in patient of coetaneous warts.

\section{References}

1. van Haalen FM, Bruggink SC, Gussekloo J, Assendelft WJ and Eekhof JA. Warts in primary schoolchildren: prevalence and relation with environmental factors. $\mathrm{Br}$ J Dermatol. 2009; 161:148-52.
2. Bruggink SC, Waagmeester SC, Gussekloo J, Assendelft WJ and Eekhof JA. Current choices in the treatment of cutaneous warts: a survey among Dutch GP. Fam Pract. 2010; 27:549-53. 
3. Rijkaart DC, Berkhof J, Rozendaal L, van Kemenade FJ, Bulkmans NW and Heideman DA. Human papillomavirus testing for the detection of high- grade cervical intraepithelial neoplasia and cancer: final results of the POBASCAM randomised controlled trial. Lancet Oncol. 2012, 13:78-88.

4. Eckert L. O., Watts D. H., Koutsky L. A., Hawes S. E., Stevens C. E., uypersJ and Kiviat N. B. A matched prospective study of human immunodeficiency virus serostatus, human papillomavirus DNA, and cervical lesions detected by cytology and colposcopy. Infect. Dis. Obstet. Gyneco. (1999); 7:158-164.

5. Pazyar N, Feily A and Yaghoobi R. Macrophage migration inhibitory factor as an incriminating agent in dermatological disorders. Indian $\mathbf{J}$ Dermatol 2013;

6. Stosic-Grujicic S, Stojanovic I and Nicoletti F. MIF in autoimmunity and novel therapeutic approaches. Autoimmun Rev 2009; 8: 244-249.

7. Chouhy D, Bolatti EM, Piccirilli G, Sánchez A, Fernandez Bussy $R$ and Giri AA. "Identification of human papillomavirus type 156 , the prototype of a new human gammapapillomavirus species, by a generic and highly sensitive PCR strategy for long DNA fragments". J. Gen. Virol. 2013; 94 : 524-33.

8. Lynch MD, Cliffe J and MorrisJones R. Management of cutaneous viral warts. BMJ. 2014 $: 27 ; 348$.

9. Palefsky J. M., Holly E. A., Ralston M. L and Jay N. Prevalence and risk factors for human papillomavirus infection of the anal canal in human immunodeficiency virus (HIV)positive and HIV-negative homosexual men. J. Infect. Dis. 1998; 177:361-367.

10.Sun X. W., Kuhn L., Ellerbrock T. V., Chiasson M. A., Bush T. J and Wright T. C. Jr. Human papillomavirus infection in women infected with the human immunodeficiency virus. N. Engl. J. Med. 1997; 337:1343-1349.

11. George M. and Vaughan J. In vitro cell migration as a model for delayed hypersensitivity. Proc. Soc. Exp. Biol. Med. 1962; 111: 514-21.

12. Calendra $T$ and Bucala $R$. Macrophage migration inhibitory factor (MIF): a glucocorticoid counter- regulator within the immune system, Critical Reviews in Immunology. 1997; 17: 77-88.

13. Schober A, Bernhagen $J$ and Bernhagen J. -Stabilization of therosclerotic plaques by blockade of macrophage migration inhibitory factor after vascular injury in apolipoprotein E-deficient mice Circulation. 2004 ; 109:380-385.

14. Gregory J. L., Morand E. F., McKeown SJ, Ralph JA, Hall P and Yang YH. -Macrophage migration inhibitory factor induces macrophage recruitment via CC chemokine ligand 2, $\|$ Journal of Immunology. 2006; 77: 8072-8079.

15. Nishihira $J$, Ishibashi $T$ and Fukushima $\mathbf{T}$. Macrophage migration inhibitory factor (MIF): Its potential role in tumor growth and tumor- associated angiogenesis. Ann N Y Acad Sci. 2003; 995: 171-2.

16. Calandra T, Bernhagen J, Metz C. N, Spiegel L. A, Bacher $M$ andDonnelly $\mathbf{T}$. MIF as a glucocor-ticoid-induced modulator of cytokine production. Nature. 1995; 377, 68-71.

17. Bucala $R$ and Donnelly SC. Macrophage migration inhibitory factor: a probable link between inflammation and cancer. Immunity. 2007; 26: 281-5.

18. Abe R, Peng T, Sailors J, Bucala $R$ and MetzCN . Regulation of the CTL response by macrophage migration inhibitory factor. Journal of Immunology.2001; 166:747-753. 
SOHAG MEDICAL JOURNAL

Vol. 21 No.2 July 2017

91

PDF created with pdfFactory Pro trial version www.pdffactory.com 
SOHAG MEDICAL JOURNAL Vol. 21 No.2 July 2017
Serum levels of macrophages migration inhibitory factor Amaal M Mohammed.et al

92 